\title{
Review Article \\ Colon Capsule Endoscopy: Review and Perspectives
}

\author{
David Friedel, Rani Modayil, and Stavros Stavropoulos \\ Winthrop University Hospital, Mineola, NY, USA \\ Correspondence should be addressed to David Friedel; dfriedel@winthrop.org
}

Received 26 June 2016; Accepted 16 August 2016

Academic Editor: Eiji Sakai

Copyright (C) 2016 David Friedel et al. This is an open access article distributed under the Creative Commons Attribution License, which permits unrestricted use, distribution, and reproduction in any medium, provided the original work is properly cited.

Colon capsule endoscopy utilizing PillCam COLON 2 capsule allows for visualization potentially of the entire colon and is currently approved for patients who cannot withstand the rigors of traditional optical colonoscopy (OC) and associated sedation as well as those that had an OC that was incomplete for technical reasons other than a poor preparation. We will then describe the prior experience and current status of colon capsule endoscopy.

\section{Introduction}

Colorectal cancer (CRC) is the second most prevalent cancer in women and third most common cancer in men globally [1]. In the United States and numerous other nations, optical colonoscopy (OC) is the most utilized modality for CRC screening but several other screening options are available internationally including radiographic and endoscopic modalities that diagnose premalignant or malignant lesions such as flexible sigmoidoscopy, computed tomographic colonography (CTC), and air contrast barium enema and most recently colon capsule endoscopy. There are also stool-based exams which are most sensitive for cancers and high-grade adenomas (fecal occult blood and immunochemical test and fecal DNA). Colon capsule endoscopy is attractive because of its noninvasive nature and potential ability to visualize much of the colon similar to optical colonoscopy. However, its detriments include lesser sensitivity than OC for adenomas and cancers, need for more involved preparation than OC, cost/reimbursement, and inability for therapy and biopsy. These factors and the lack of trained video readers have minimized use in the United States, but there has been moderately extensive use in Europe. It is currently approved for subjects who had incomplete colonoscopy due to technical reasons such as endoscope looping and for subjects with lower gastrointestinal hemorrhage who are less than apt candidates for optical colonoscopy. We will review the current literature concerning colon endoscopy and discuss prospects for the future.

\section{Technical Aspects}

Virtually all experience with colon capsule endoscopy has been with the first two generations of the Colon Capsule (Given Imaging Ltd., Yoqneam, Israel) device which is similar to that has been used for small bowel imaging for almost two decades. There are three main components in the Given Imaging diagnostic system: an ingestible capsule (second generation) endoscope, a data recorder, and the RAPID viewing workstation. The second-generation CCE (PCC-2) dimensions are $11.6 \times 31.5 \mathrm{~mm}$ [2] (Figure 1). It has some similarities to the small intestinal capsule (battery life) and the esophageal capsule (two cameras) but has the unique critical feature of an adaptive frame rate (AFR) (Table 1). The AFR is activated once the capsule is in small bowel (the rate in the esophagus and stomach is 14 images/s) and alternates between 4 images each second when the capsule is stationary and changes to 35 images/second when the capsule is moving [2]. The AFR thus both conserves battery life and allows better viewing when moving. This AFR results from bidirectional communication between the capsule and data recorder. Views are comparable to traditional endoscopy but with better resolution (Figure 2). The visualization system for viewing the video after download at the workstation is similar to the Given small bowel capsule.

Contraindications are similar to the small bowel capsule and include intestinal obstruction, high-grade intestinal structures, gastroparesis and other severe motility issues, and poor colon preparation. The manufacturer discourages use in patients with cardiac electrical devices. 
TABLE 1: PillCam 2 properties.

\begin{tabular}{lc}
\hline Battery life & 10 hours \\
Cameras & 2-one at each end \\
Lenses & 3 \\
Angle view & 172 degrees \\
$\begin{array}{l}\text { Esophageal-gastric } \\
\text { frame rate }\end{array}$ & $14 / \mathrm{sec}$ \\
Small bowel colon & AFR-4/s(stationary) $32-35 / \mathrm{s}$ \\
(motion)
\end{tabular}

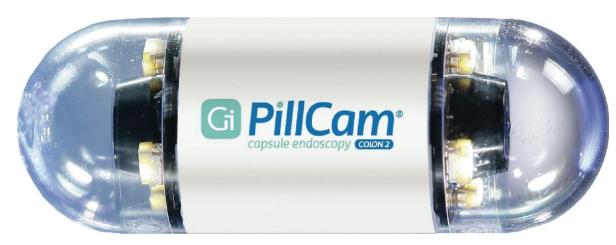

Figure 1: PillCam 2 COLON capsule.

\section{Colon Preparation}

Colon preparation is a particular issue for the use of the colon capsule because the capsule is incapable of maneuvering around or washing away debris. In addition, the 10-hour battery life may not allow pan-colonic visualization. The proportion of subjects passing the capsule rectally is referred to as the excretion rate. Therefore, the various regimens are typically more rigorous than for colonoscopy preparation. The capsule is capable of giving feedback to the patient as to its location via vibrations and display instructions [2]. Depending on the particular protocol, the patient, for instance, would take a prokinetic if the capsule is in the stomach for a prolonged period of time and a booster regimen once the device is mobile when villi are detected [2]. One group employed polyethylene glycol (PEG) as both the initial regimen and the booster with the with a prokinetic (metoclopramide, erythromycin, etc.) given after the initial regimen [10]. The capsule was excreted $86 \%$ of the time but good visualization of the entire colon was only noted in $60 \%$ [10]. Sodium phosphate solution is commonly used as a booster in Europe but has limited use in the United States because of renal toxicity concerns [11]. One group noted $100 \%$ sensitivity for findings seen on subsequent colonoscopy after a prep including three days of clear liquids and combined sodium phosphate, PEG, and bisacodyl [3].

\section{Validation and Comparative Studies}

The design of colon capsule studies to date predominantly consisted of performing a colon capsule exam and then the subjects would get a subsequent optical colonoscopy usually on the same or next day and often utilizing the same preparation. The tandem study design assumed that OC was the gold standard, though occasionally the capsule noted polyps not seen on the initial colonoscopy [12]. The first generation colon capsule had only moderate sensitivity and specificity for colon polyps and was hindered by only fair colon cleansing rates perhaps related to nonstandardized colon preparation. These issues are well demonstrated in a publicized NEJM study with 328 subjects who had known or suspected colonic disease [13]. Only $72 \%$ had a good to excellent cleansing and $8 \%$ did not excrete the capsule. Sensitivity and specificity for all polyps $\geq 6 \mathrm{~mm}$ were $64 \%$ and $84 \%$, respectively. Sensitivity and specificity for advanced adenoma were $73 \%$ and $79 \%$, respectively. A major concern was that only 14 out of 19 (74\%) cancers were detected by the capsule exam [13]. There was a clear positive correlation of capsule exam sensitivity for polyps and cancer and the degree of cleansing of the colon [13]. A meta-analysis of 837 subjects receiving the first generation colon capsule demonstrated similar sensitivity and specificity for polyps $\geq 6 \mathrm{~mm}$ as the NEJM study, and 16 of 21 cancers were identified (76\%) [14].

Fortunately, the second-generation colon capsule introduced in 2009 had much improved detection features including an increased angle of view of $172^{\circ}$ (the cameras at each end allow almost $360^{\circ}$ viewing), an improved data recorder, and most importantly the feature of the adaptive frame rate (AFR) as mentioned above which would allow optimal visualization when the capsule is moving [15]. Seven series (Table 2) using the CCE-2 consisting of over 1000 subjects demonstrate a remarkably better sensitivity and specificity than the first generation with aggregate sensitivities for polyps $\geq 6 \mathrm{~mm}>85 \%$ and about $90 \%$ for polyps $\geq 10 \mathrm{~mm}$. Virtually all of the cancers were detected by the capsule. There were few adverse effects usually related to the prep. The largest series [7] enrolled 884 subjects but 689 were included in the analysis and the most common exclusion was inadequate preparation or too rapid colon transit, and thus the excellent sensitivity and specificity may be skewed because of this exclusion. Notably all four cancers were detected by capsule. A meta-analysis of over 2400 subjects approximately equally divided by the CCE-1 and CCE-2 use demonstrated a sensitivity for polyps $\geq 6 \mathrm{~mm}$ of $58 \%$ (CCE-1) and $86 \%$ (CCE-2), respectively. The CCE-1/CCE-2 sensitivity for polyps $\geq 10 \mathrm{~mm}$ was $54 \% / 87 \%$, respectively [16]. The specificities were about the same for the two versions.

There has been only few studies to date which compared colon capsule with CT colonography [17]. One study design had subjects who had an initial incomplete colonoscopy and then had both CCE-2 and CTC exams. OC was repeated if there were significant findings on either of the two antecedent modalities. CCE had about twice the sensitivity as CTC for polyps $\geq 6 \mathrm{~mm}$ ( 25 versus $12 \%$ ). Lesions missed by CTC tended to be small and in the proximal colon [17]. There were no missed cancers in a clinical follow-up of 20 months [17]. A Japanese cohort of 66 patients with a prior history of colon polyps or cancer had both CCE and OC. Per-patient and perpolyp sensitivity was $94 \%$ and $87 \%$, respectively. Both these studies suggest that CCE may have a role in detecting small (even flat) polyps in a well prepped colon. In another series, 50 subjects with positive FIT stool test had OC, CCE, and CTC [18]. The sensitivity for CCE and CTC for polyps $\geq 6 \mathrm{~mm}$ was both about $88 \%$, but CCE was preferred by patients over CTC. The sensitivity of CCE for colon lesions and its safety after incomplete colonoscopy has been well validated [19]. 


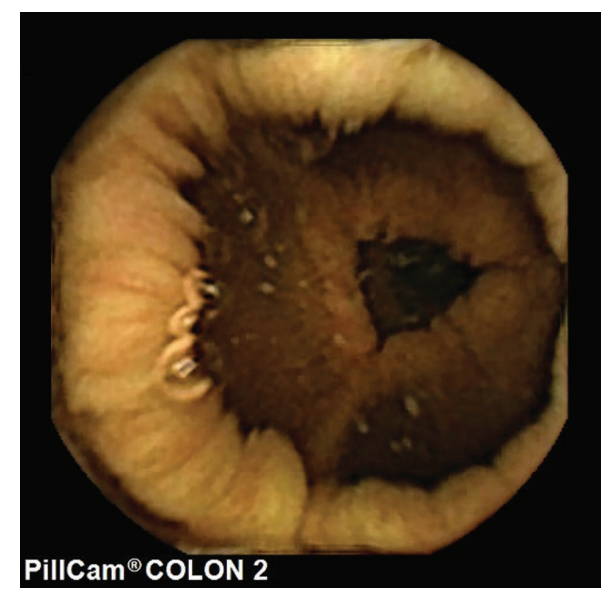

(a)

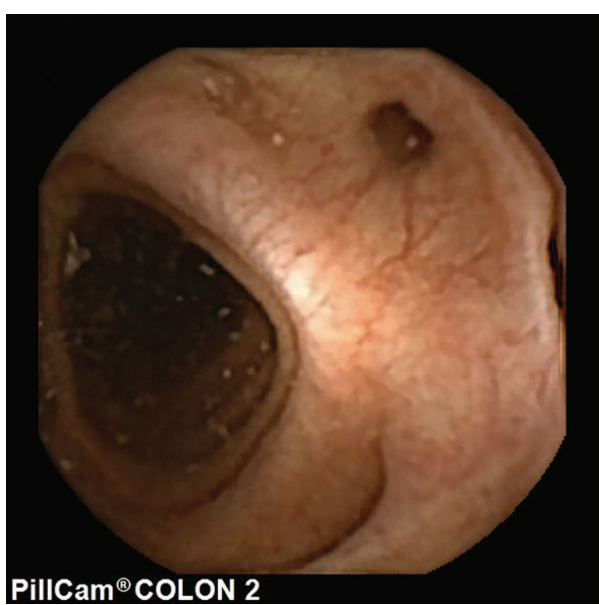

(c)

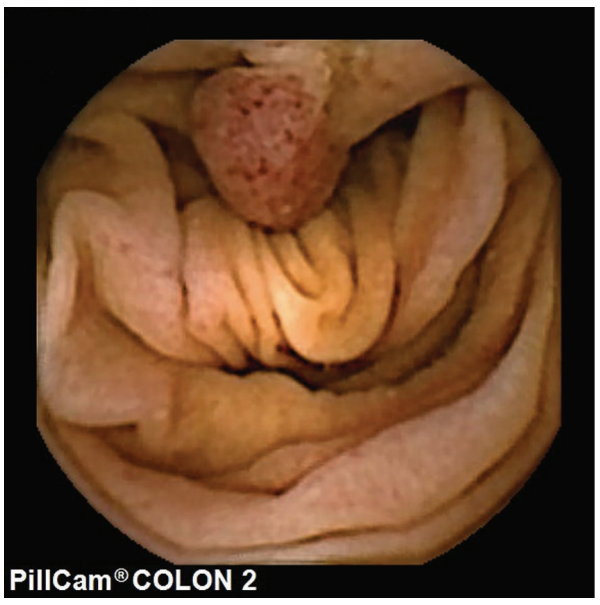

(e)

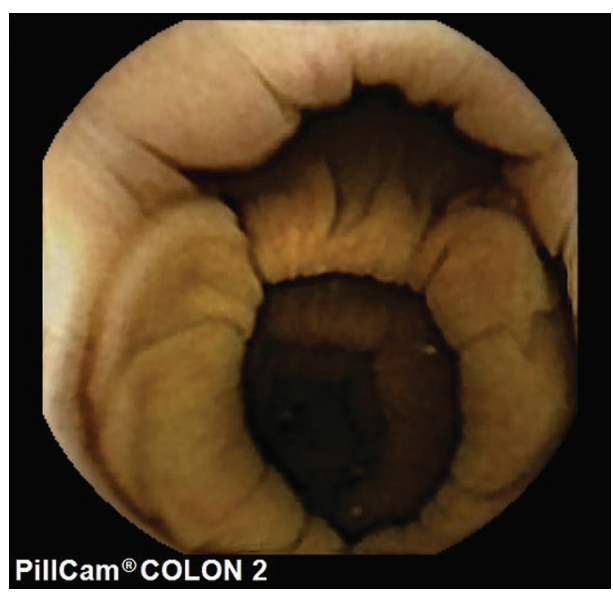

(b)

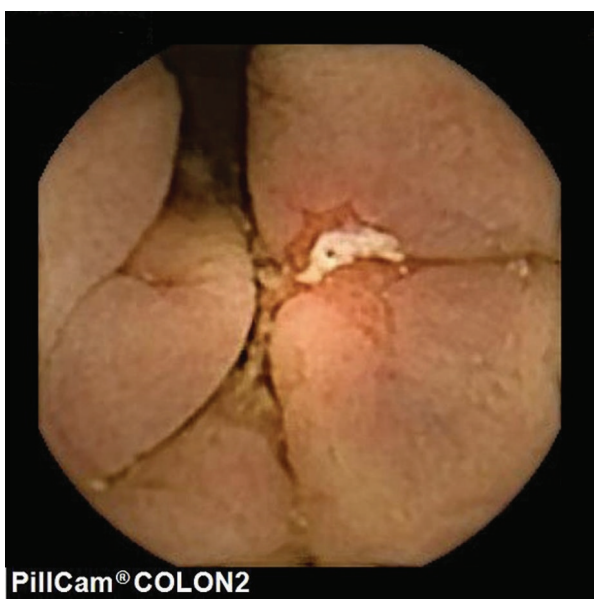

(d)

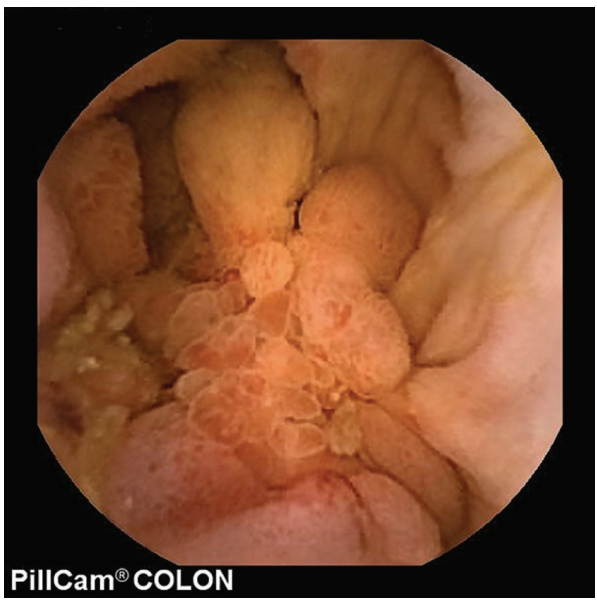

(f)

Figure 2: (a) Transverse colon. (b) Ascending colon. (c) Diverticulum. (d) Crohn's disease. (e) Colon polyp. (f) Colon cancer.

\section{Inflammatory Bowel Disease}

Currently, CCE is not supported by evidence as a diagnostic modality for the surveillance of patients with suspected or known inflammatory bowel disease $[2,20]$. The diagnosis of ulcerative colitis requires histologic verification. Patients with known UC have accurate assessment of mucosal inflammation by capsule and this may be useful after new drug introduction, alteration, or discontinuation [11, 21]. One study noted that CCE sensitivity and specificity for active colon 
TABLE 2: PillCam COLON 2 in colon polyp and cancer detection.

\begin{tabular}{|c|c|}
\hline Lead author/N/year/reference & Results and comments \\
\hline Akyuz/28/2016/[3] & $\begin{array}{l}\text { Only } 28 \text { of } 62 \text { subjects in this study focusing on prep had tandem colonoscopy. 6/28 subjects had } \\
\text { polyps in 5-10 mm range. Sensitivity, specificity, PPV, and NPV were } 100 \%, 92 \%, 93 \%, 100 \%\end{array}$ \\
\hline Morgan/50/2016/[4] & $\begin{array}{l}\text { Of the } 50 \text { patients who had tandem capsule and OC } 30 \% \text { and } 14 \% \text { had polyps } \geq 6 \text { and } 10 \mathrm{~mm} \text {, } \\
\text { respectively. For lesions } \geq 10 \mathrm{~mm} \text { on OC, capsule sensitivity was } 100 \% \text { and specificity } 100 \% \text {. For } \\
\text { polyps } \geq 6 \mathrm{~mm} \text {, capsule sensitivity was } 93 \% \text { and specificity } 80.0 \% \text {. The excretion rate was } 65 \%-61 \% \\
\text { of studies considered adequate cleansing }\end{array}$ \\
\hline Hollerhan/62/2014/[5] & $\begin{array}{l}62 \text { subjects with (+) FIT had tandem capsule/colonoscopy. Sensitivity/specificity for polyps }>6 \\
\text { and } 10 \mathrm{~mm} \text {, respectively, was } 95 / 65 \% \text { and } 89 / 96 \% \text {, respectively. } 92 \% \text { had adequate cleaning with } \\
73 \% \text { excretion rate }\end{array}$ \\
\hline Hagel/24/2014/[6] & $\begin{array}{l}\text { Sensitivity/specificity for polyps } \geq 6 \mathrm{~mm} \text { and } 10 \mathrm{~mm} \text { was } 72 / 91 \text { and } 75 / 100 \% \text {, respectively. Adequate } \\
\text { cleansing } 90 \% \text {. Excretion rate } 71 \% \text {. Extracolonic GI pathology }>50 \%\end{array}$ \\
\hline Rex/884/2013/[7] & $\begin{array}{l}\text { Largest series. Sensitivity/specificity for polyps } \geq 6 \text { and } 10 \mathrm{~mm} \text { was } 88 / 82 \text { and } 92 / 95 \% \text {, respectively. } \\
\text { AC } 80 \% \text {. ER } 91 \%\end{array}$ \\
\hline Spada/117/2015/[8] & $\begin{array}{l}8 \text { European centers: } 109 \text { subjects analyzed. Sensitivity/specificity for polyps } \geq 6 \text { and } 10 \mathrm{~mm} \text { was } \\
84 / 64 \text { and } 88 / 95 \% \text {, respectively. AC } 85 \% \text {. ER } 81 \%\end{array}$ \\
\hline Eliakim/104/2009/[9] & $\begin{array}{l}\text { Initial validating series for CCE- } 2 \text {. Data from } 98 \text { subjects. Sensitivity/specificity for polyps } \geq 6 \text { and } \\
10 \mathrm{~mm} \text { was } 89 / 76 \text { and } 88 / 89 \% \text {, respectively. AC } 78 \% \text {. ER } 81 \%\end{array}$ \\
\hline
\end{tabular}

inflammation in UC were $89 \%$ and $75 \%$, respectively [22]. A CCE study in 30 pediatric subjects noted a sensitivity and specificity for disease activity of $96 \%$ and $100 \%$, respectively [23]. There is even less literature on CCE use in Crohn's disease and there is a concern for capsule retention due to strictures. There is however significant precedent for capsule use in small intestinal Crohn's disease and some have lauded the colon capsule as a "pan-enteroscopic" test in CD [24].

\section{Prospects for the Future: Obstacles and Hopeful Developments}

One small series of seven subjects touted colon capsule as a primary and sole therapy for presurgery diagnosis of GI malignancy [25], but the evidence to date suggests that the colon capsule is at best a strong ancillary modality to optical colonoscopy in colon cancer screening. Thus, colon capsule will have a similar niche in screening as CTC and stool DNA in that positive findings will prompt a subsequent optical colonoscopy. However, colon capsule will likely to be shown to be superior to the other two modalities in that like optical colonoscopy there will be direct visualization of potential or actual abnormalities and thus likely greater specificity. In addition, colon capsule would be more attractive than CTC because of lack of radiation and need for intravenous access. One analysis demonstrated CC to be much more costeffective than CTC [26]. Colon capsule like CTC and OC requires a prep and in fact a more prolonged and involved preparation. This together with the relatively prohibitive cost of CC (comparable to OC), current lack of trained video readers (in the US), and lack of biopsy/therapy capabilities are the Achilles heel of colon capsule. Hopefully a preparation regimen that probably does not contain sodium phosphate can be formulated, standardized, and shown to be both effective in cleansing and tolerable. One possibility is a PEG/ascorbic acid combination [27]. There was a dearth of supporting data to include CC as a screening option at the time of the multidisciplinary consortium that generated guidelines colorectal cancer screening in 2008 [28]. Colon capsule is likely to be included in the next set of guidelines for screening.

The reading of the colon capsule typically takes much longer than that for small bowel capsule endoscopy, and the entire gastrointestinal tract is visualized with potential extracolonic findings and pathology. These findings (analogous to CTC) may benefit the patient or alternatively create anxiety and extra testing with incumbent cost. One series of 24 subjects receiving CC noted esophagus/gastric/small intestine pathology in 7/9/14 subjects, respectively [14]. As mentioned, a pan-endoscopic exam would be useful in assessment of Crohn's disease and also drug effect throughout the GI tract.

Technological advances have improved capsule visualization and interpretation. Capsule software allows accurate measurement of a polyp even at a distance [2]. Spectral imaging color enhancement has been incorporated in the Given small bowel capsule and could conceivably be used in the colon version [29]. Computer-based learning of video interpretation and computer-aided analysis have been demonstrated [30,31].) Experimental prototypes of a capsule steerable in real time and a capsule capable of imaging without a colon prep have been described but are impractical for now $[32,33]$.

\section{Conclusion}

Colon capsule endoscopy has emerged as a sensitive screening modality for colorectal polyps and cancer ancillary to optical colonoscopy, but the studies to date have not validated it as a primary screening test. It will remain in the armamentarium of ancillary colon screening tests together with CT colonoscopy and stool DNA test. There has been moderately widespread use in Europe, but its use in the 
United States is limited to relatively few centers, and this is likely to change in the future as there are likely further validating studies, standardization of preparation regimens, lower cost, technological improvements, and more trained readers. It has been used mainly for colon polyp and cancer screening, but it may be proven useful in inflammatory bowel disease and those taking anti-inflammatory drugs. Its noninvasive feature is particularly attractive to patients relative to optical colonoscopy. This may be an option for approximately one-third of all eligible Americans who have not availed themselves of colon screening. In the US, it is predominantly used for the approved indications of incomplete colonoscopy due to technical reasons other than inadequate preparation and in those persons who are unable or unwilling to have optical colonoscopy.

\section{Competing Interests}

The authors declare that they have no competing interests.

\section{References}

[1] E. El Zoghbi and L. C. Cummings, "New era of colorectal cancer screening," World Journal of Gastrointestinal Endoscopy, vol. 8, no. 5, pp. 252-258, 2016.

[2] C. Spada, C. Hassan, and G. Costamagna, "Colon capsule endoscopy," Gastrointestinal Endoscopy Clinics of North America, vol. 25, no. 2, pp. 387-401, 2015.

[3] Ü. Akyüz, Y. Yılmaz, A. T. İnce, B. Kaya, and C. Pata, "Diagnostic role of colon capsule endoscopy in patients with optimal colon cleaning," Gastroenterology Research and Practice, vol. 2016, Article ID 2738208, 5 pages, 2016.

[4] D. R. Morgan, P. R. Malik, D. P. Romeo, and D. K. Rex, "Initial US evaluation of second-generation capsule colonoscopy for detecting colon polyps," BMJ Open Gastroenterology, vol. 3, no. 1, Article ID e000089, 2016.

[5] G. Holleran, R. Leen, C. O’Morain, and D. McNamara, “Colon capsule endoscopy as possible filter test for colonoscopy selection in a screening population with positive fecal immunology," Endoscopy, vol. 46, no. 6, pp. 473-478, 2014.

[6] A. F. Hagel, E. Gäbele, M. Raithel et al., "Colon capsule endoscopy: detection of colonic polyps compared with conventional colonoscopy and visualization of extracolonic pathologies," Canadian Journal of Gastroenterology and Hepatology, vol. 28, no. 2, pp. 77-82, 2014.

[7] D. K. Rex, S. N. Adler, J. Aisenberg et al., "Accuracy of capsule colonoscopy in detecting colorectal polyps in a screening population," Gastroenterology, vol. 148, no. 5, pp. 948.e2-967.e2, 2015.

[8] C. Spada, C. Hassan, M. Munoz-Navas et al., "Second-generation colon capsule endoscopy compared with colonoscopy," Gastrointestinal Endoscopy, vol. 74, no. 3, pp. 581-589.el, 2011.

[9] R. Eliakim, K. Yassin, Y. Niv et al., "Prospective multicenter performance evaluation of the second-generation colon capsule compared with colonoscopy," Endoscopy, vol. 41, no. 12, pp. 1026-1031, 2009.

[10] T. Brechmann, W. Schmiegel, L. Klute, T. Rösch, and C. Pox, "Feasibility of a colon capsule overnight procedure followed by colonoscopy," Zeitschrift für Gastroenterologie, vol. 54, no. 2, pp. 146-151, 2016.
[11] C. Spada, C. Hassan, J. P. Galmiche et al., "Colon capsule endoscopy: European Society of Gastrointestinal Endoscopy (ESGE) guideline," Endoscopy, vol. 44, no. 5, pp. 527-536, 2012.

[12] N. Schoofs, J. Devière, and A. Van Gossum, "PillCam colon capsule endoscopy compared with colonoscopy for colorectal tumor diagnosis: a prospective pilot study," Endoscopy, vol. 38, no. 10, pp. 971-977, 2006.

[13] A. Van Gossum, M. Munoz-Navas, I. Fernandez-Urien et al., "Capsule endoscopy versus colonoscopy for the detection of polyps and cancer," The New England Journal of Medicine, vol. 361, no. 3, pp. 264-270, 2009.

[14] C. Spada, C. Hassan, R. Marmo et al., "Meta-analysis shows colon capsule endoscopy is effective in detecting colorectal polyps," Clinical Gastroenterology and Hepatology, vol. 8, no. 6, pp. 516-e8, 2010.

[15] R. Eliakim, "The PillCam" colon capsule for colon cancer screening: comparison between the first- and second-generation capsules," Hospital Practice, vol. 38, no. 3, pp. 110-116, 2015.

[16] C. Spada, S. F. Pasha, S. A. Gross et al., "Accuracy of firstand second-generation colon capsules in endoscopic detection of colorectal polyps: a systematic review and meta-analysis," Clinical Gastroenterology and Hepatology, 2016.

[17] C. Spada, C. Hassan, B. Barbaro et al., "Colon capsule versus CT colonography in patients with incomplete colonoscopy: a prospective, comparative trial," Gut, vol. 64, no. 2, pp. 272-281, 2015.

[18] E. Rondonotti, C. Borghi, G. Mandelli et al., "Accuracy of capsule colonoscopy and computed tomographic colonography in individuals with positive results from the fecal occult blood test," Clinical Gastroenterology and Hepatology, vol. 12, no. 8, pp. 1303-1310, 2014.

[19] K. Triantafyllou, N. Viazis, P. Tsibouris et al., "Colon capsule endoscopy is feasible to perform after incomplete colonoscopy and guides further workup in clinical practice," Gastrointestinal Endoscopy, vol. 79, no. 2, pp. 307-316, 2014.

[20] C. Spada, F. Barbaro, G. Andrisani et al., "Colon capsule endoscopy: what we know and what we would like to know," World Journal of Gastroenterology, vol. 20, no. 45, pp. 1694816955, 2014.

[21] H. Y. Shi, S. C. Ng, K. K. Tsoi et al., "the role of capsule endoscopy is mucosal inflammation in ulcerative colitis," Expert Review of Gastroenterology \& Hepatology, vol. 9, no. 1, pp. 47-54, 2015.

[22] J. Sung, K. Y. Ho, H. M. Chiu, J. Ching, S. Travis, and R. Peled, "The use of Pillcam Colon in assessing mucosal inflammation in ulcerative colitis: a multicenter study," Endoscopy, vol. 44, no. 8, pp. 754-758, 2012.

[23] S. Oliva, G. Di Nardo, C. Hassan et al., "Second-generation colon capsule endoscopy vscolonoscopy in pediatric ulcerative colitis: a pilot study," Endoscopy, vol. 46, no. 6, pp. 485-492, 2014.

[24] B. Hall, G. Holleran, and D. McNamara, "PillCam COLON 2(৫) as a pan-enteroscopic test in Crohn's disease," World Journal of Gastrointestinal Endoscopy, vol. 7, no. 16, pp. 1230-1232, 2015.

[25] C. Busegeanu, A. Fillmon, A. Stemate et al., "a series of images of digestive cancers using Pill Cam Colon2 video capsule endoscopy," Journal of Medicine and Life, vol. 7, no. 4, pp. 45294532, 2014.

[26] S. Palimaka, G. Blackhouse, and R. Goeree, "Colon capsule endoscopy for the detection of colorectal polyps: an economic analysis," Ontario Health Technology Assessment Series, vol. 15, no. 15, pp. 1-43, 2015. 
[27] F. Argüelles-Arias, M. San-Juan-Acosta, A. Belda et al., "Preparations for colon capsule endoscopy. Prospective and randomized comparative study between two preparations for colon capsule endoscopy: PEG 2 liters + ascorbic acid versus PEG 4 liters," Revista Espanola de Enfermedades Digestivas, vol.106, no. 5, pp. 312-317, 2014.

[28] B. Levin, D. A. Lieberman, B. McFarland et al., "Screening and surveillance for the early detection of colorectal cancer and adenomatous polyps, 2008: a joint guideline from the American Cancer Society, the US multi-society task force colorectal cancer, and the American College of Radiology," CA: A Cancer Journal for Clinicians, vol. 58, no. 3, pp. 130-160, 2008.

[29] L. Negreanu, C. M. Preda, D. Ionescu et al., "Progress in digestive endoscopy: Flexible Spectral Imaging Colour Enhancement (FICE)-technical review," Journal of Medicine and Life, vol. 8, no. 4, pp. 416-422, 2015.

[30] H. Watabe, T. Nakamura, A. Yamada, Y. Kakugawa, S. Nouda, and A. Terano, "Assessment of an electronic learning system for colon capsule endoscopy: a pilot study," Journal of Gastroenterology, vol. 51, no. 6, pp. 579-585, 2016.

[31] L. Meziou, A. Histace, F. Precioso et al., "Computer-assisted segmentation of videocapsule images using $\alpha$-divergence-based active contour in the framework of intestinal pathologies detection," International Journal of Biomedical Imaging, vol. 2014, Article ID 428583, 10 pages, 2014.

[32] A. Arezzo, A. Menciassi, P. Valdastri et al., "Experimental assessment of a novel robotically-driven endoscopic capsule compared to traditional colonoscopy," Digestive and Liver Disease, vol. 45, no. 8, pp. 657-662, 2013.

[33] H. Chatrath and D. K. Rex, "Potential screening benefit of a colorectal imaging capsule that does not require bowel preparation," Journal of Clinical Gastroenterology, vol. 48, no. 1, pp. 52-54, 2014. 


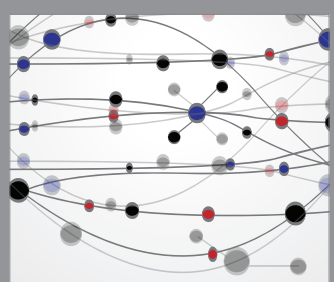

The Scientific World Journal
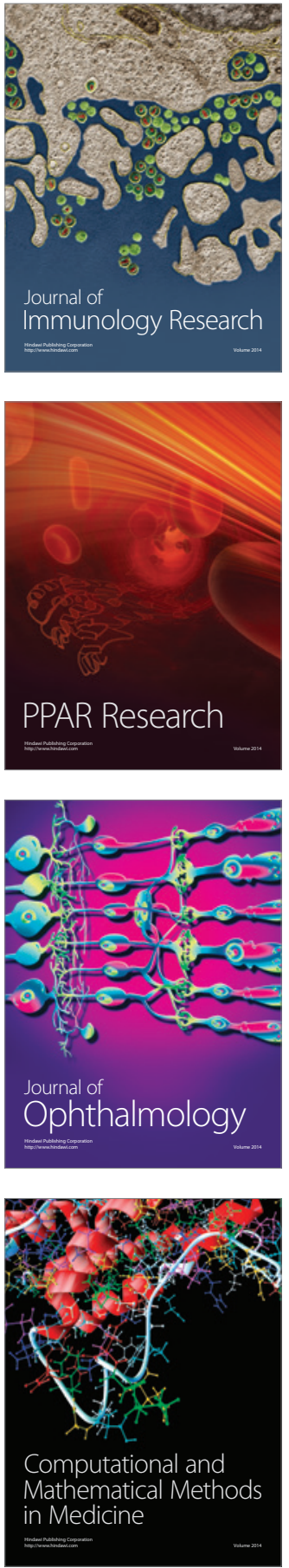

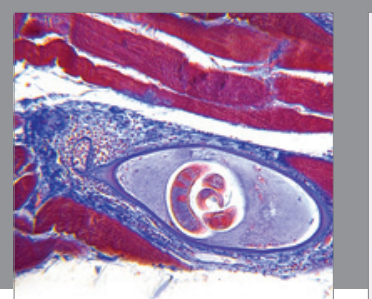

Gastroenterology Research and Practice

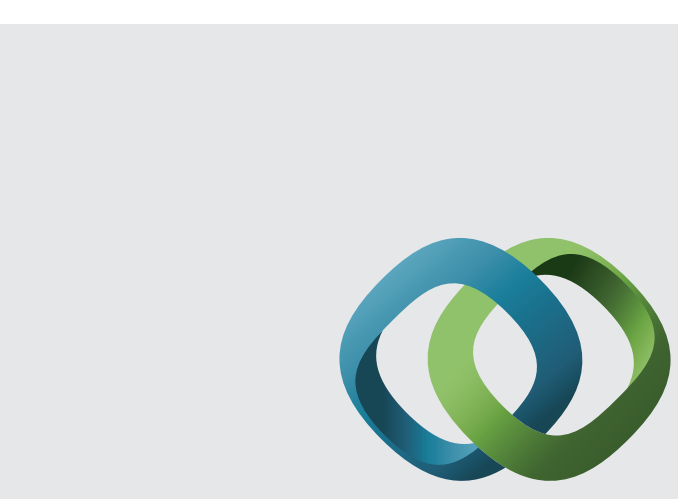

\section{Hindawi}

Submit your manuscripts at

http://www.hindawi.com
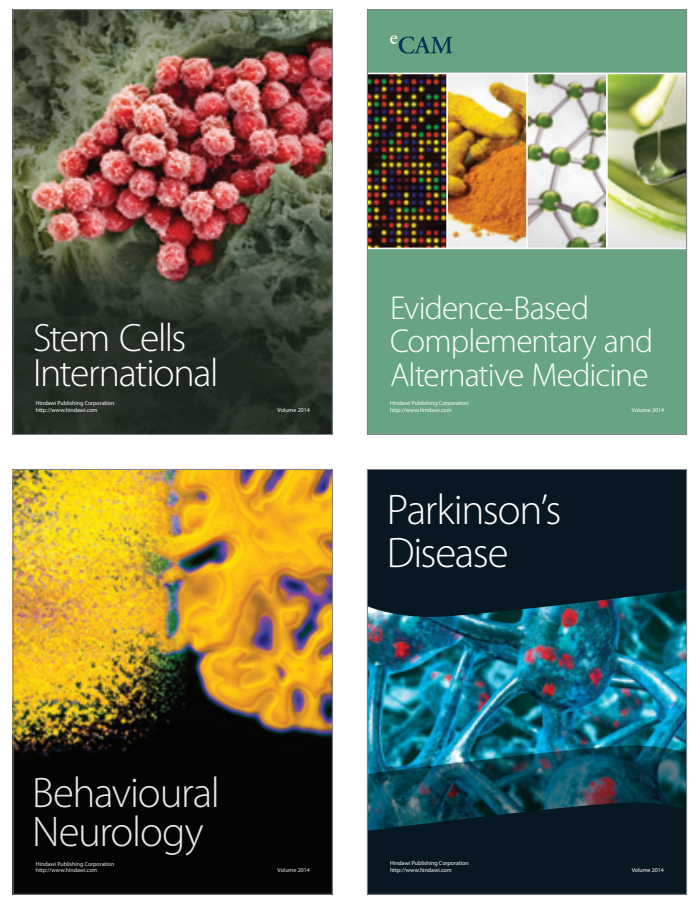
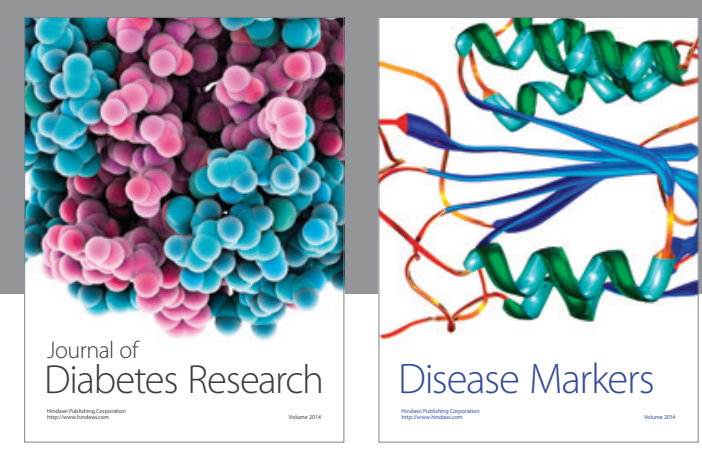

Disease Markers
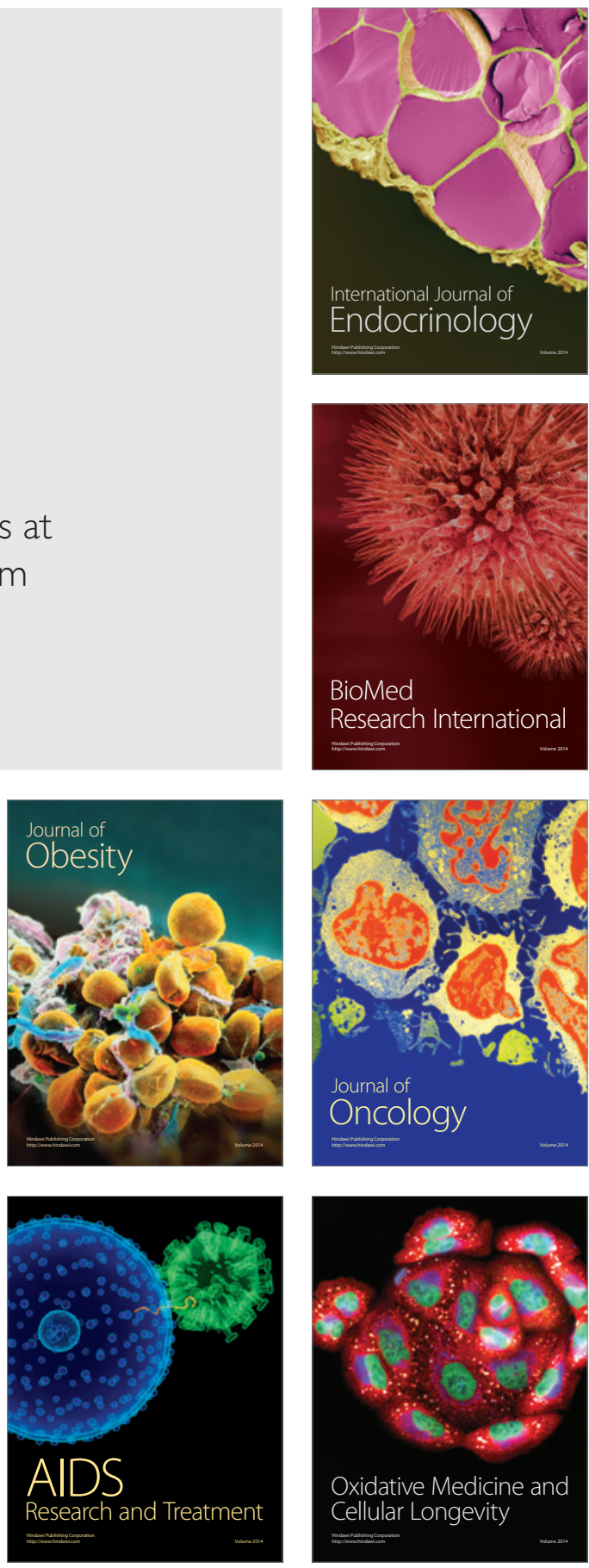